\title{
Bienestar Psicológico y Budismo: Experiencias y significados en practicantes de Budismo en el Perú
}

\section{Psychological wellbeing and Buddhism: practitioner's experiences and meanings of Buddhism in Peru}

\author{
Andrea Elías Roca Rey* \\ Carlos Flores Galindo Rivera \\ Universidad Peruana de Ciencias Aplicadas, Perú \\ (Rec.: noviembre de 2016 - Acept.: abril de 2017)
}

\section{Resumen}

El objetivo de esta investigación fue explorar las experiencias y significados del bienestar psicológico en practicantes de la división joven del Budismo de Nichiren Daishonin en el Perú. Se contó con la participación de 10 jóvenes, 5 mujeres y 5 hombres entre 20 y 32 años de edad, practicantes del Budismo de Nichiren Daishonin residentes de Lima Metropolitana. Empleando un diseño cualitativo, la información recabada tomó como referencia los sistemas conversacionales propuestos por González Rey (2006). El presente estudio muestra que todas las experiencias y significados de los jóvenes participantes cuentan con la presencia de los seis factores propuestos por Ryff y Keyes (1995) para alcanzar el bienestar. Señala al budismo como un medio o camino por el cual los participantes han llegado a alcanzar el bienestar psicológico o la Revolución Humana. Este concepto presente en las conversaciones conducidas es percibido como la mejora de la calidad de vida y desarrollo personal de los budistas. Finalmente, se identificó la importancia del componente comunitario en los practicantes de budismo ya que es considerado como un factor esencial para alcanzar el bienestar psicológico.

Palabras clave: bienestar, budismo, experiencias, revolución humana, componente comunitario.

\begin{abstract}
The purpose of this research is to explore the experiences and meanings of psychological well being among practitioners of the young division of Nichiren Daishonin Buddhism in Peru. The sample consisted in 10 people (5 women and 5 men) ranging from 20 to 32 years old, who were Nichiren Daishonin Buddhism followers and lived in Lima City. The study was conducted through a qualitative approach, and the conversational system proposal created by González Rey (2006) was used as a tool to gather information. The results show that all six factors proposed by Ryff and Keyes (1995) to achieve wellness are found in the participants' experiences and meanings. Therefore, Buddhism is displayed as a means by which participants have sought to achieve psychological wellbeing or the Human Revolution. This concept came up in the conducted conversations, and it is thought to improve Buddhists' quality of life and personal development. Finally, this research highlights the importance of the community component, since it is considered essential in order to achieve psychological well-being.
\end{abstract}

Keywords: well-being, buddhism, experiences, human revolution, communitary component.

\footnotetext{
* Correspondencia a: Andrea Elías Roca Rey. Universidad Peruana de Ciencias Aplicadas, Facultad de Psicología. Dirección:
} Prolongación Primavera 2390, Lima, Perú. E-mail: andrea.rocarey@gmail.com. 


\section{Introducción}

Estudiar el concepto de bienestar psicológico en practicantes de budismo permite identificar que, para este grupo de personas, el budismo es un medio para alcanzar el bienestar psicológico. Este estudio invita a profundizar en el conocimiento de las coincidencias entre el budismo y la psicología, ahondando en la subjetividad de este colectivo.

\section{Justificación}

Resulta importante estudiar el bienestar psicológico ya que, a nivel individual, toma en cuenta aspectos cotidianos y cualitativos de la persona vinculados a la felicidad. En la misma línea, está relacionado con la salud, tanto a nivel fisiológico como emocional y cómo esta última es fundamental para el bienestar. Por ello, se estudia el aspecto del bienestar en toda la actividad humana como parte de la salud en su más amplio sentido. Se sabe que cuando una persona se siente bien consigo misma, es más creativa, productiva y sociable; ve el futuro de manera positiva; presenta buena capacidad para trabajar y relacionarse con su entorno y, lo más importante, se caracteriza por su felicidad (González, García-Viniegras \& Ruiz, 2014).

Actualmente, se están estudiando distintas terapias que permiten a las personas poder llegar a un bienestar psicológico a través de la exploración de sus propios recursos y llegando a lo más profundo de su ser. El budismo contribuye a esta exploración con técnicas como la meditación, favoreciendo el autoconocimiento de la persona en sus aspectos más profundos (Bustamante, 2004).

\section{Marco teórico}

El Bienestar Psicológico se encuentra integrado por distintos componentes que permiten lograr una satisfacción personal con la vida. Ello implica un convenio entre la persona misma y su propio entorno, su presente y su pasado, lo material y lo social; que en su conjunto y armonía logran la realización personal y llevan a una satisfacción con la propia vida (Anguas-Wong et al., 2007; Zubieta, Fernández \& Sosa, 2012).

El concepto de bienestar puede definirse en base a tres elementos: su carácter subjetivo, en base a la propia experiencia de la persona; su dimensión global, porque incluye la valoración del sujeto en todas las áreas de su vida y la apreciación positiva, ya que su naturaleza va más allá de la mera ausencia de factores negativos (Diener, 1994).

El bienestar psicológico se produce en relación a la satisfacción con la vida y a un balance entre las expectativas y los logros personales. También, se asocia a una buena calidad de vida, al disfrute personal, donde los estados emocionales positivos son los que predominan así como las expectativas y logros alcanzados (González et al., 2014).

Ryff y Keyes (1995) subrayan los siguientes seis factores fundamentales para poder lograr el bienestar psicológico:
1. La auto-aceptación: se refiere a la capacidad de poder sentirse bien consigo mismo, ser consciente de las propias limitaciones y tener una actitud positiva hacia sí mismo

2. Relaciones positivas: destaca la importancia de tener amigos y relaciones estables en las que se pueda confiar. Para el bienestar psicológico es fundamental la capacidad de amar y querer.

3. Dominio del entorno: constituye la capacidad de cada individuo para crear o elegir entornos que puedan ser favorables.

4. Autonomía: describe la capacidad de la persona de sostener su propia individualidad frente a distintos contextos sociales. Para así resistir mejor la presión social y regular el propio comportamiento.

5. Propósito en la vida: donde lo fundamental es poder tener objetivos y metas claras.

6. Crecimiento personal: evalúa la capacidad que tiene cada persona para poder generar condiciones aptas para lograr desarrollar sus potencialidades y seguir creciendo como persona.

Como concluye Ryff (1989): "el bienestar psicológico mide no sólo si el sujeto se siente feliz, sino cómo se encuentran las diferentes dimensiones de su funcionamiento positivo que tendrán una relación teóricamente fundamentada con su autorrealización y crecimiento personal" (S. Chávez, 2008, p. 10). En este sentido, para alcanzar el bienestar psicológico es necesario que todas las dimensiones estén desarrolladas para lograr la autorrealización, el crecimiento personal y la felicidad del sujeto.

Recientemente, se ha destacado cómo el bienestar psicológico puede incrementarse utilizando algunas técnicas del budismo. El bienestar psicológico ha cobrado importancia en los últimos años, por su posibilidad de contribución a la comprensión de la salud y el bienestar en los sujetos (S. Chávez, 2008). De igual manera, Schnettler et al. (2011) señalan que, en la sociedad actual, las personas son cada vez más conscientes de su autocuidado y buscan en el mercado aquello que contribuya a su salud y bienestar (Denegri et al., 2014).

El trabajo de Rojas (2011) sobre la felicidad en jóvenes practicantes del budismo de Nichiren Daishonin corrobora este argumento afirmando que los jóvenes budistas cuentan con un nivel de felicidad mayor de los que no practican. De igual manera, S. Chávez (2008) encuentra que los practicantes de yoga, técnica utilizada por el budismo, puntúan significativamente más alto en bienestar psicológico.

Asimismo, otros estudios destacan la existencia de una asociación significativa entre variables de tipo cognitivo (rendimiento académico, perfil atencional), el bienestar psicológico (A. Chávez, 2006) y el mindfulness (Almansa et al., 2014; Gutiérrez, 2011). La meditación o mindfulness, constituye el corazón de la meditación budista (Almansa et al., 2014; Mañas, 2009). También se afirma que promueve variables de crecimiento personal y mejora el auto concepto; es decir, contribuye al bienestar psicológico y autovalía (Almansa et al., 2014). 
El budismo es una filosofía acerca de la vida que no hace distinciones entre el ser humano y el medio donde habita (Lama, 2014). Propone una interrelación entre todas las formas de vida que comprenden una compleja red que trasciende el entendimiento humano y considera a la humanidad como parte de la naturaleza. Acepta a las personas tal y como son, con debilidades y defectos, presentes y pasados (Ciancaglini, s.f.). No trata de imponer una religión, sino de facilitar herramientas para que las personas se puedan sentirse bien consigo mismas y con su entorno (Berzin, 1988).

Se entiende como un medio para poder llegar a la felicidad (Ciancaglini, s.f.). Implica el sentirse completo, encontrar un equilibrio entre el bien y el mal; así como lograr el objetivo de vida de cada persona lo cual se conoce como el trascender (Bustamante, 2004). Cuando este equilibrio se experimenta, se encuentra una felicidad que no se entiende como ordinaria (Sánchez, 2001). Es una vía espiritual que trata básicamente de qué y cómo trascender, en términos de ir más allá del sufrimiento, angustia, dolor y ansiedad (Mikulas, 2007). Lo ideal no es solo alcanzar la felicidad individual, sino incorporar a todos aquellos que comparten el mismo deseo de ser libres de sufrimiento y de encontrar el estado final de bienestar (Ekman, Davidson, Ricar \& Wallace, 2005).

El budismo de Nichiren Daishonin, una de las ramas del budismo basado en las enseñanzas del monje japonés Nichiren, destaca el logro de la Revolución Humana como uno de los principios más importantes (Rojas, 2011). Este concepto implica identificar y cuestionar las debilidades personales y/o defectos que inhiben la plena expresión del potencial positivo inherente. Este proceso dinámico de transformación personal invita a considerar los acontecimientos negativos como oportunidades de mejora. La finalidad del desarrollo de las virtudes personales es el ascenso progresivo del individuo en los estados de vida previamente mencionados, hasta alcanzar el estado de budeidad o felicidad plena.

Durante este proceso resulta importante el apoyo reciproco que se brindan los creyentes, para identificar sus aspectos de mejora y establecer como meta el desarrollo de sus cualidades y virtudes. El budismo de Nicheren Daishonin es una práctica diaria, donde realizan un compromiso con ellos mismos de no ceder jamás ante las dificultades y remontarse victoriosos sobre sus sufrimientos. Al mismo tiempo, es el juramento de ayudar a los demás a revelar esta ley en sus propias vidas y alcanzar la felicidad o bienestar (Soka Gakkai Internacional, 2008). El objetivo general en esta investigación será explorar las experiencias y significados del bienestar psicológico en practicantes de la división joven del Budismo de Nichiren Daishonin en el Perú.

\section{Método}

Se utilizó una metodología cualitativa empleando los sistemas conversacionales propuestos por
González Rey (2006). Adoptando así un alcance descriptivo (Hernández, Fernández y Baptista ,2006), la naturaleza cualitativa de esta investigación trata de identificar la estructura dinámica de los comportamientos y manifestaciones para así identificar la naturaleza profunda de las realidades (Martínez, 2006).

\section{Participantes}

La selección de los participantes tuvo carácter accidental (Ramos, 2009) por inscripción propia conforme a un calendario y horarios prefijados para el desarrollo de las entrevistas. La muestra se compuso de 10 jóvenes, 5 mujeres y 5 hombres, practicantes del Budismo de Nichiren Daishonin entre 20 y 32 años de edad, residentes de Lima Metropolitana en distritos pertenecientes al sector considerado de nivel intermedio o bajo de la capital. La mayoría de los participantes cuenta con estudios secundarios y actualmente se encuentran cursando estudios superiores y trabajando para poder financiarlos. El criterio de elección fue la saturación de la información al encontrar respuestas similares en las categorías propuestas Ryff y Keyes (1995). Todos los jóvenes participaron voluntariamente en las entrevistas mostrando colaboración y compromiso con la investigación.

\section{Técnica de recolección de información}

Los sistemas conversacionales, como técnica de recolección de información, permiten al investigador poner distancia del foco de las preguntas y así impulsar la naturalidad y autenticidad de la conversación. Asimismo, se fomenta que los participantes expresen dudas y experiencias, se facilita la emergencia de sentidos subjetivos al tomar diferentes formas en las argumentaciones, las expresiones verbales y las emociones (González Rey, 2006).

Para incitar las reflexiones de los participantes y construir su propia identidad, se adoptan temas generales (González Rey, 2006). Dos preguntas eje centraron la conversación de esta investigación: ¿Cómo se inició en el budismo? y ¿Qué es para usted el bienestar psicológico? La finalidad de las mismas fue conseguir que los participantes pudieran expansionarse acerca de sus creencias e ideas sobre el budismo y el bienestar psicológico.

La conversación, como técnica, representa un proceso reflexivo inducido por el investigador en el cual el participante llega a sus propias conclusiones. Estas tienen lugar al condensar el participante su propia experiencia, permitiendo identificar trechos de información relevantes para dar cuenta de la experiencia subjetiva. Igualmente, al hablar sobre experiencias propias, los participantes permiten aportar información que pudo pasar desapercibida en investigaciones previamente revisadas (González Rey, 2006).

\section{Procedimiento}

La investigación se inicia con un estudio piloto basado en entrevistas a personas budistas 
residentes en Lima. Tras la valoración de tres expertos en metodología y una primera prueba piloto, la guía conversacional empleada fue debidamente modificada acorde a la respuesta obtenida y las consideraciones recibidas. Se optó por iniciar la conversación con una pregunta abierta para fomentar el esparcimiento del participante en su elocución sobre su experiencia como practicante de budismo y la percepción que tiene acerca del Bienestar. Finalmente, al realizar un segundo sondeo incluyendo las revisiones respectivas, se obtuvo un mejor resultado, por lo que se considera la nueva guía no estructurada en la metodología.

Un centro budista ubicado en el distrito de San Isidro, en Lima, fue contactado a través del círculo personal de la investigadora por intermedio de un pariente practicante de budismo. La investigadora pudo pasar por un periodo de familiarización con algunos miembros del centro. Todos los participantes dieron su consentimiento por escrito mediante un formulario donde se les explicaba los fines de la investigación y debían confirmar que su participación era voluntaria.

Si bien se facilitó el acceso al centro budista, fue difícil coordinar las citas con el grupo de los participantes. El centro estaba lejos de sus zonas de residencia para llegar a la hora acordada. Asimismo, al haber seleccionado al grupo joven, muchos de ellos estudiaban y trabajaban, y dificultaba poder establecer un horario de reuniones.

\section{Análisis de la Información}

Para el registro y análisis de la información recopilada en las entrevistas, se desarrolló un cuadro conformado por cuatro ejes temáticos: Motivación, Experiencia de Bienestar Psicológico (dominios de Ryff), Conceptos del Budismo de Nichiren Daishonin y Concepto de Bienestar Psicológico según participantes.

En estos ejes temáticos se emplazaron las citas de la conversación sostenida con cada participante. Ello con la finalidad de facilitar el análisis de las experiencias de los participantes en forma ordenada y completa $y$, por consiguiente, posibilitar el resultado del objetivo de esta investigación. Este proceso reveló la importancia del componente de comunidad.

Para corroborar y complementar dichos resultados, se realizó un análisis de contenido de las entrevistas (Krippendorff, 1990; Schwandt, 1997, citado en Denegri et al., 2014). Siguiendo lo propuesto por Strauss y Corbin (1990), inicialmente se desarrolló una codificación abierta para determinar conceptos a partir de los datos revelados de acuerdo a la revisión de los protocolos de las entrevistas. Estos códigos fueron agrupados posteriormente, siendo la repetición de la información incluida en el relato el criterio para la formación de las categorías (Denegri et al., 2014). De este análisis se obtuvo un resultado coherente con el primero que se realizó, permitiendo la elaboración de un árbol de categorías (véase Fig.1). De esta manera, resultó destacable el mayor énfasis de la dimensión comunitaria del bienestar en el budismo.

\section{Resultados y Discusión}

Para describir las experiencias y significados del bienestar psicológico en practicantes de la división joven del Budismo de Nichiren Daishonin en el Perú, se expone a continuación el árbol de categorías. La figura 1 muestra los motivos que llevaron a los participantes a practicar dicha filosofía de vida. Posteriormente, se pasa a analizar algunos de los factores comunes que se encuentran en el budismo y el concepto de bienestar definido por Ryff y Keyes (1995). Finalmente, se examina la importancia del componente comunidad en los conceptos del budismo y su definición de bienestar como un elemento distintivo respecto a la teoría de Ryff y Keyes (1995), así como las implicaciones de los resultados obtenidos.

En primer lugar, respecto a la motivación para iniciarse en esta filosofía de vida, se observa que todos los participantes mencionaron tener un contacto con el budismo a través de sus padres, como evidencia la siguiente cita:

Nací en un hogar budista, mis papás practicaban. El que trajo el budismo a mi casa fue mi papá, eh... en el año... en los setenta. Entonces, como nací en un hogar budista, siempre de chiquito iba a las reuniones. No le tomaba mucha importancia, hasta que, en la juventud, a eso cuando tenía 16 años (Sujeto 6, 2016).

Sin embargo, a partir de lo expuesto, si bien hubo un contacto previo con el budismo en la vida del participante (al igual que la de la mayoría), esta no fue la motivación principal por la cual decidieron seguir dicha filosofía de vida. La adopción del budismo llegó algunos años después y por voluntad propia.

Cuando me fui al doctor [en la adolescencia], eh... me explicaron que, tenía una enfermedad llamada ovario poli quístico, y que esto hacia que mi cuerpo y mi rostro lucieran diferentes, entonces eh... yo, por ver eso, me hizo sentir muy mal (...) llegué ya hasta un momento de pensar que ya ni siquiera quería vivir, fue muy fuerte para mí, fue muy fuerte, y cuando pasó más tiempo y pasaron más cosas, que también hicieron que tocara muy hondo (...) Entonces fue así como yo comencé a practicar de forma más seria [el budismo] (Sujeto 1, 2016).

Esta cita evidencia algunas de las razones por las que se toma la decisión de adoptar esta filosofía. Asimismo, el resto de participantes mostraron que su compromiso profundo hacia el budismo se inicia a raíz de una crisis personal.

Mikulas (2007) comenta que el budismo es una vía espiritual que trata básicamente de qué y cómo trascender, en términos de ir más allá del sufrimiento, angustia, dolor y ansiedad. Entre los problemas personales que han atravesado los 
participantes, se encuentra como factor común la falta de confianza en sí mismos. Detonantes decisivos, tales como presentar algún defecto físico o contar con bajos recursos económicos, conducen a experimentar un gran malestar y una auto desvalorización de sí mismos y, en algunos casos, se llega incluso a pensar en el suicidio.

Figura 1. Árbol de Categorías: Bienestar Psicológico y Budismo

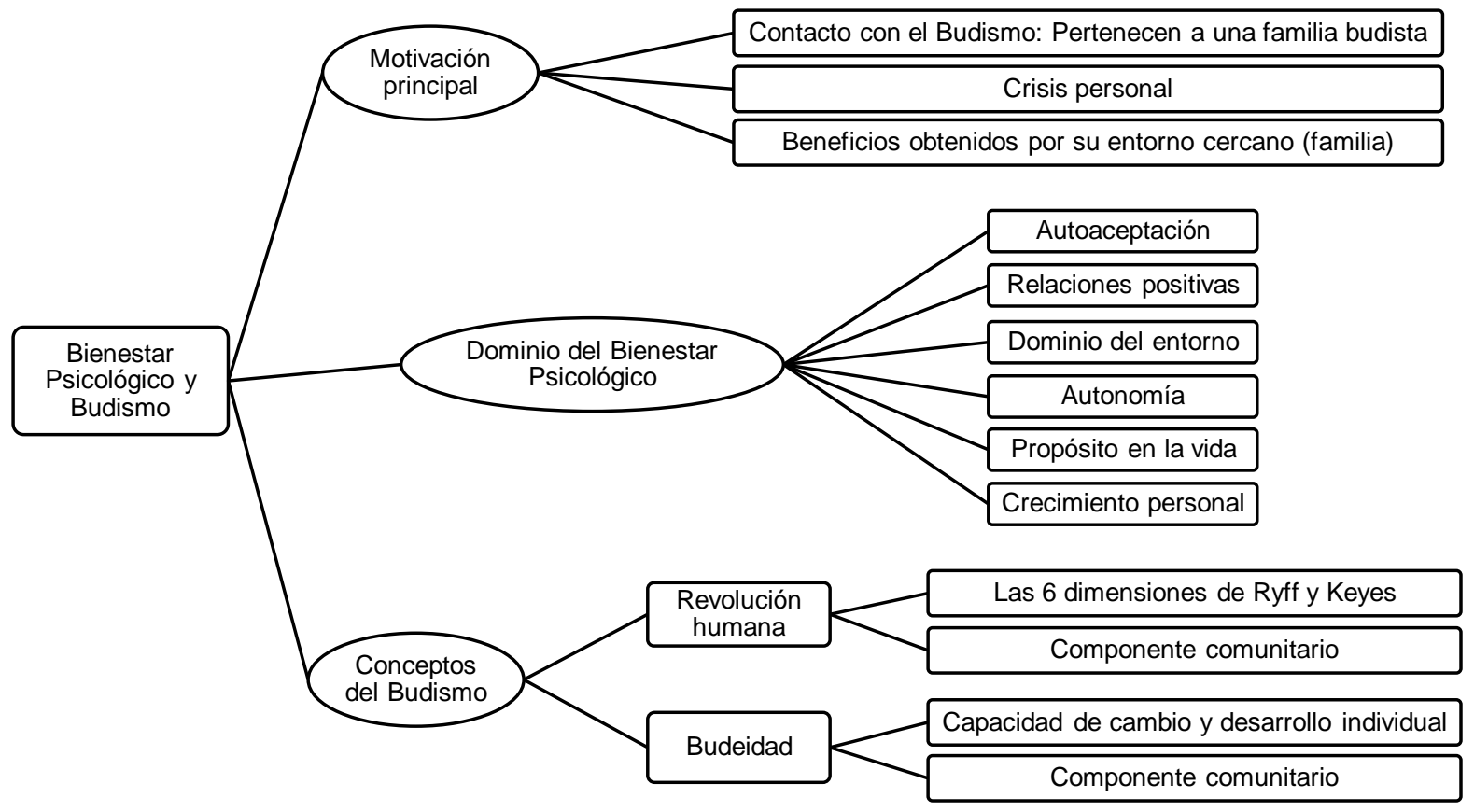

Otras situaciones críticas en los participantes, detonantes de la búsqueda de ayuda o apoyo en la práctica del budismo son los problemas familiares. Se observa que el compromiso hacia esta filosofía de vida conduce a las personas al encuentro de un camino hacia la mejora. Ciancaglini (s.f.) señala que el budismo se entiende como un medio para poder llegar a la felicidad. Esto implica encontrar un equilibrio entre el bien y el mal, y lograr el objetivo de vida de cada persona, el cual se entiende como el trascender (Bustamante, 2004). La siguiente cita refleja este argumento:

Mi papá me dio un amor muy duro también, porque mi papá ha sido militar, entonces su formación ha sido muy rígida, con muchos parámetros...el budismo me hizo entender muchas cosas...de que, también mediante mi cambio interior, podía hacer que mi papá cambie y mejore conmigo. Entre una de las tantas orientaciones me dijeron que para tener el papá que quiero debo querer el papá que tengo (...) Entonces también me preocupe en darle más amor a mi papá, fui cambiando yo y también cambio él y eso generó un bienestar (Sujeto 4, 2016).

La metodología utilizada permitió que, a través del dialogo, surgiera de manera espontánea el concepto de Revolución Humana como elemento clave para entender el significado de bienestar en este grupo. Dicha revolución integra una lucha continua con el poder, aceptar tanto lo positivo como lo negativo de uno mismo. Una vez logrado, se busca identificar y cuestionar las debilidades personales $\mathrm{y} / \mathrm{o}$ defectos que inhiben la plena expresión del potencial positivo inherente. Este proceso dinámico de transformación personal invita a considerar los acontecimientos negativos como oportunidades de mejora (Rojas, 2011). Al igual que lo señalado por otros estudios previos, todo problema es considerado por los budistas como un beneficio, ya que, con el paso del tiempo, nos llevará a convertirnos en mejores personas.

La Revolución Humana se presenta como un proceso de revolución interna que saca todo lo positivo de la persona hasta llegar a conseguir el bienestar. De esta forma, refleja una similitud con el concepto de bienestar psicológico, donde el componente emocional ocupa un lugar importante.

La Revolución Humana es una revolución interior (...) el beneficio más grande que te da el budismo, es el poder hacer tu propio cambio interior (...) básicamente es que tú ya veas las cosas desde tal punto que no digas ¿Por qué me está pasando esto? Sino mediante esto yo voy a poder desarrollarme más. Verlo más como una oportunidad más que como quejarse o algo así (...) Las actitudes que tú tienes, las vas a ver reflejadas automáticamente...[El participante menciona que todo cambio de uno mismo se puede ver reflejado en el entorno] (Sujeto 4, 2016).

La importancia y emoción que le otorgan los practicantes del budismo de Nichiren Daishonin a la Revolución Humana a través de sus experiencias, es uno de los puntos más importantes y centrales en esta investigación. A través de la definición de este concepto se facilita el entendimiento de cómo 
alcanzar el bienestar a través del budismo, sus componentes, y cómo define la idea de bienestar. La siguiente cita ilustra el concepto de Revolución Humana entendido como la lucha constante que implica un cambio interior que permite la autoaceptación para poder desarrollarse y crecer a nivel personal.

Yo practicaba duro, practicaba bastante duro, pero yo me sentía mal conmigo misma, porque esa era mi tendencia básica, menospreciarme. Entonces, y por qué yo digo que me renové cuando deje eso, no es que yo haya dejado de practicar, no, yo he seguido practicando, pero llegar a ese punto de entender que yo debo cambiar, es bien, digamos lo más difícil, y a eso se le llama Revolución Humana (...) yo te puedo decir que ese cambio es cuando uno ya supera eso ¿no? Cuando uno ya supera sus debilidades y logra elevar su estado de vida (Sujeto 1, 2016).

Como se mencionaba en la introducción, según varios autores (A. Chávez, 2006; S. Chávez, 2008; Véliz Burgos, 2012), Ryff y Keyes (1995) destacan seis factores fundamentales para alcanzar el bienestar psicológico: la auto-aceptación, relaciones positivas, dominio del entorno, autonomía, propósito en la vida y el crecimiento personal. Estos conceptos están presentes en las experiencias de vida expuestas por los practicantes de budismo.

Anguas-Wong et al. (2007) mencionan que el bienestar psicológico trasciende el estado de ánimo y la reacción emocional. Expresa el sentir positivo y el pensamiento constructivo de la persona acerca de sí misma y se relaciona con los aspectos físicos, psíquicos y sociales. Las siguientes experiencias ilustran cómo los participantes encuentran en el budismo una vía o un medio que les ha permitido auto-aceptarse; es decir, quererse y valorarse tal y como son (Ciancaglini, s.f.):

(...) Nosotros los budistas practicamos diariamente y esa práctica te permite desarrollar, primero sentirte bien contigo y de alguna manera cuando salgas a la calle o lo que tengas algo que hacer sentirte más protegida siempre y cuándo tener siempre cuidado (Sujeto 3, 2016).

(...) Gracias a las orientaciones de señoritas que me brindaron y he escuchado también las orientaciones, creo que me fortalecieron pues ¿no? y empecé a aceptarme y a quererme como yo soy ¿no? como "F" y eso fue (Sujeto 5, 2016).

Así, cuando una persona se siente bien consigo misma, es más creativa, productiva y sociable, ve el futuro de manera positiva, presenta buena capacidad para trabajar y relacionarse con su entorno y, lo más importante, se caracteriza por su felicidad (González et al., 2014). De igual manera, a partir de las conversaciones desarrolladas, se pudo apreciar la importancia que los budistas otorgan a las buenas relaciones de amistad. En este sentido, es destacable la preocupación que poseen por mantener un entorno armonioso, seguro, cariñoso y confiable. Comentan cómo, a través del budismo, han desarrollado la capacidad de escucha, apoyo y, sobre todo, el valor de la tolerancia y de respeto a lo distinto:

Soy más paciente, trato de escucharlos mejor, no solo de oírlos, sino de escucharlos de poder entender en qué los puedo ayudar ¿no? $Y$ aconsejarlos de la mejor manera posible cómo ellos pueden solucionar sus problemas (Sujeto 3, 2016).

(...) Todas mis amistades me encantan, así sean por ejemplo eh... mucho me dicen tú tienes amistades de todo tipo me dicen, o sea, unos que son así súper igual como tú, (risas) positivo así alegres, pero otros son como todo lo contrario a ti, por ejemplo, los chicos así súper vándalos (...) también tengo amigos de todo tipo, toda religión, y yo con todos me llevo muy bien y me alegra porque a veces compartimos también, porque cada uno tiene algo que compartir. Entonces siempre trato de sacarle ese lado positivo de cada persona (...) con todos puedo compartir y también aprender de ellos algo (Sujeto 5, 2016).

Nuevamente, se observa cómo emerge uno de los factores expuestos por Ryff y Keyes (1995): la importancia de las relaciones positivas; el valorar al otro y poder desarrollar la capacidad de amar, de dar, de aprender de los demás y compartir. A través de la práctica del budismo, las personas se vuelven más conscientes de lo que sucede en su entorno, desarrollando la capacidad de ayuda y empatía hacia el mismo. Por lo tanto, en esta filosofía de vida, lo ideal no es solo alcanzar la felicidad individual, sino incorporar a todos aquellos que comparten el mismo deseo de ser libres de sufrimiento y encontrar el estado final de bienestar (Ekman et al., 2005). Se deduce que el bienestar incondicional, conocido por los budistas como Revolución Humana, sobrepasa al estado de bienestar psicológico tal y como es definido por la psicología.

Es fundamental estar bien con el entorno. No obstante, hay que saber diferenciar también cuándo es favorable y ayuda a crecer como personas; es decir, hay que distinguir cuando suma y no resta. Así, Ryff y Keyes (1995), A. Chávez (2006) y S. Chávez (2008) agregan la importancia del dominio del entorno para alcanzar el bienestar. La siguiente cita expresa cómo el budismo brinda las herramientas para poder decir no, para alejarse de lo negativo, de lo que no ayuda en el desarrollo personal.

Lo que me enseña el budismo es que eh... debo estar relacionado siempre con personas que me sumen pues ¿no? en cambio si estoy relacionado con un entorno que es destructivo, yo creo que a la larga me voy a absorber a eso. Entonces, si estoy en un ambiente que es positivo con personas que luchan por algo o que quieren lograr algo más allá de lo personal, yo creo que eso influencia de manera positiva dentro del entorno (Sujeto 7, 2016).

El budismo resalta el valor del factor señalado por Ryff y Keyes (1995) como autonomía. Esta es 
definida como la capacidad de la persona para sostener su propia individualidad frente a distintos contextos sociales y así resistir mejor la presión social y regular el propio comportamiento. Almansa et al. (2014) y Mañas (2009) mencionan que diferentes técnicas como la meditación o mindfulness, las cuales constituyen el corazón de la meditación budista, promueven variables de crecimiento personal contribuyendo así al bienestar psicológico y la autonomía.

(...) Mis amigas todas quieren pensar igual, todas quieren pensar lo mismo, y yo, no. Yo como que un poco que, hacia lo que para mí estaba bien y mis amigas me decían, "pero por qué eres así, ¿ya no quieres parar con nosotras no?, ya no eres buena amiga porque ya no quieres ser como nosotras". $Y$ yo misma me di cuenta, o sea, que ya no, entonces yo me di cuenta que era muy difícil que me deje influenciar (...) lo que hacemos con la práctica, es ver la naturaleza de la persona, cómo es esa persona (Sujeto 1, 2016).

Por otro lado, como se mencionó anteriormente, se han recogido momentos claves en la vida de cada uno de los participantes debido a que han marcado el inicio de su práctica en el budismo de Nichiren Daishonin. Cada una de las experiencias los llevó a tomar la decisión de adoptar esta filosofía y encontrar en ella una meta o un propósito de vida y la fuerza para poder lograrlo.

Diversos autores (Córdova, 2004; González et al., 2014) refieren que el buen funcionamiento psicológico no se reduce solo a los momentos de placer o hedónicos, sino que también incluye la autorrealización, las metas y los planteamiento de objetivos para alcanzar un estado de satisfacción. En las conversaciones con los participantes, destaca la autosatisfacción alcanzada al compartir el camino hacia el bienestar por medio de la práctica del budismo. Se observa como propósito de vida el poder ayudar a los demás a encontrar la plenitud que ellos describen haber alcanzado.

(...) Poder transmitir a otras personas, para que esas personas, así también como yo encontré, digamos estabilidad, digamos ahora recién, te puedo decir ahora recién que sí, que también las mismas personas lo puedan encontrar, evidentemente hay personas que van a pasar por cosas mucho más fuertes que lo que yo he pasado (...) pero, que esas personas que me rodean también, sientan lo mismo, que puedan también sentir lo mismo. Entonces eso es lo que a mí me motiva a seguir viviendo, existiendo. Yo creo que si no tuviera esa sensación de que estoy aquí por algo, entonces yo sentiría que no tiene sentido que esté aquí. Pero es lo que da sentido a mi vida. [la participante comenta como gracias al budismo superó sus problemas y se dió cuenta de que su propósito de vida era compartir el budismo con los demás como medio de alcanzar un bienestar] (Sujeto 1, 2016).

Todo lo mencionado anteriormente lleva al último de los factores señalado por Ryff y Keyes (1995) para alcanzar el bienestar psicológico. Este es el crecimiento personal. Cada uno de los participantes muestra en su diálogo cómo han logrado generar condiciones aptas para desarrollar sus potencialidades y seguir creciendo como persona.

(...) Esta práctica te permite a ti sentirte bien contigo mismo y no dejarte influenciar por el medio ambiente ¿no? Entonces como en el medio ambiente a veces está algo negativo en el cual vivimos la misma sociedad yo quiero ser ese cambio [Menciona cómo el sentirte bien te lleva a actuar bien $y$ poder crecer o desarrollarte por ti mismo] (Sujeto 2, 2016)

Aceptando los aspectos negativos que tienes de tu personalidad, de tu forma de ser, y cuando ya los aceptas puedes eh... empezar un cambio que dependiendo de la magnitud de lo que tú has aceptado y siempre teniendo la disposición (Sujeto 3, 2016).

Se observa cómo el budismo ha sido un medio para tomar la decisión de alcanzar un equilibrio entre los aspectos negativos y positivos de los participantes, aceptándose y queriéndose tal y como son. Esto les permite desarrollarse, crecer y poder al mismo tiempo compartir sus experiencias a modo de ayuda hacia el entorno.

El budismo es una filosofía de vida que funciona como vía conducente al bienestar psicológico por medio del logro de los seis factores fundamentales que menciona la teoría de Ryff y Keyes (1995). Dicho de otra forma, permite auto-aceptarnos, mantener relaciones positivas con el entorno, no dejarnos influenciar, poseer autonomía, conseguir un propósito de vida que lleve a trazar metas que motiven a vivir y, así, poder desarrollarse.

En este estudio, el budismo se manifiesta como una filosofía de vida. A pesar de coincidir con el concepto de religión en muchos aspectos, tal y como señala Durkheim, una religión es un sistema solidario de creencias y prácticas relativas a cosas sagradas, es decir, separadas, prohibidas; creencias y prácticas que unen en una misma comunidad moral, llamada Iglesia, a todos los que se adhieren a ella (Trejo, 2010).

Adicionalmente, Ashboul (2005) señala que la verdad religiosa es una verdad absoluta, y como tal, está por encima de cualquier sospecha y de cualquier intento de modificación, transformación o evolución porque es divina. Por el contrario, la verdad filosófica se caracteriza por constituir una verdad que tiene muchas formas de interpretar y comprender cada tema.

Diversos autores (Khantipalo, 1992; Nyanaponika,1986; Rahula,1974: snelling,1999, como se citó en, Mikulas, 2007) sostienen que Buda es una comunidad educativa puesto que en el budismo no existe una divinidad o un salvador, no hay credos o dogmas, rituales o adoración y nada es asumido por la fe.

Lo expuesto anteriormente llama a reflexionar de nuevo sobre el budismo como una filosofía, pues 
tiene como meta el poder llegar por uno mismo, a través de sus propios recursos, a evolucionar y transformarse en mejor persona. Para el budista, todos somos seres con las capacidades necesarias para poder superarnos a nosotros mismos y así encontrar paz interior. No busca asemejarse a un ser todo poderoso sino encontrar un equilibrio propio por el que llegar a la auto-aceptación.

Asimismo, en el budismo se pueden observar personas que buscan, a través de su propia experiencia vital, mejorar y superarse a sí mismas bajo sus propias metas e ideales a alcanzar. Por lo tanto, tal como lo menciona Berzin (1988), el budismo trata de dar herramientas a las personas para que se puedan sentir bien consigo mismas y con su entorno.

Yo me fui dando cuenta que el budismo, más que una religión, del ejercicio de orar todos los días, era una filosofía de vida también, que les enseñaba a vivir ¿no? (Sujeto 8, 2016).

Si bien en el dialogo de los diez participantes se encuentra cuestiones de fe, oración y creencias, como se ha venido mencionando, no existe una divinidad a la cual veneran, ya que como los participantes mencionan, todos poseemos las capacidades y recursos necesarios para alcanzar el estado de budeidad. Es decir, no hay alguien superior al que rendir culto, sino más bien un conjunto de actitudes e ideas orientadas a conseguir por sus propios medios el tomar la decisión de vivir mejor. Este último aspecto es el factor que nos hace diferenciar el significado que le otorgan los budistas a su práctica, pues es un estilo de vida que ellos optan seguir por voluntad propia. Mikulas (2007) señala que el budismo es un conjunto de prácticas e investigación libre por el cual la persona por sí misma conoce la verdad y la utilidad de las enseñanzas.

Finalmente, este estudio revela la importancia que brindan los participantes al componente comunitario en la definición que presentan de bienestar. La preocupación hacia el entorno que les rodean así lo corrobora. Si bien, buscan el equilibrio interno para sentirse bien consigo mismos, es significativo que todos los participantes muestren un deseo de bienestar común. A través de su práctica, intentan ser guías para que otros miembros de su entorno puedan lograrlo también. Esta es la principal diferencia con el concepto de bienestar psicológico y es descrita de la siguiente manera:

(...) El propósito de la lucha es que nosotros no solo buscamos la felicidad para uno mismo, sino también para los demás, a través de nuestro cambio personal, no solo buscar nuestro bienestar, sino también el de los demás.

(...) Desarrollar más empatía y preocupación por las demás personas, no solo por nuestra familia sino por las personas que están mal o están sufriendo o tienen alguna situación que no les permite ser felices en ese momento (Sujeto 3, 2016).
Es interesante encontrar cómo la práctica del budismo logra desarrollar en las personas un sentimiento de empatía y conciencia sobre cómo las acciones y cambios individuales, ya sean positivos o negativos, influyen en el entorno. Así, buscan compartir su experiencia de vida con los demás de forma que consiguen no solo su desarrollo personal, sino brindar herramientas que fomenten una mejoría a nivel global que, finalmente, les proporciona bienestar psicológico.

Los resultados demuestran que los seis factores de la Teoría de Ryff y Keyes (1995), mencionados también por A. Chávez (2006), S. Chávez (2008) y Véliz Burgos (2012), se entrelazan con la definición expuesta de bienestar por los participantes, esta se diferencia precisamente por el último punto y es el componente de comunidad. Para los practicantes del budismo no existe la idea de un desarrollo individual, pues toda acción se ve reflejada en el entorno. Ello indica que, si una persona crece a nivel personal, las personas que lo rodean también cambiaran su manera de comportarse con ella. Por ende, el entorno también genera un cambio que fomenta bienestar en el ambiente donde se desempeñan.

(...) Lo que sí encontré en el budismo es eso, o sea, eh... que no se centra solamente en el desarrollo personal ¿no? sino que a través de los principios que tiene, eh... poder pues este transformar tu entorno (...) ahora tengo mucha más consciencia por ejemplo para actuar... o sea, veo las consecuencias que pueda traer, no solamente para mí, sino las personas que me rodean (Sujeto 7, 2016).

Haber encontrado un medio para el bienestar personal y social a través de la práctica del budismo permite a los informantes conseguir un equilibrio, mantener relaciones positivas con el entorno, tener un propósito de vida y llegar a un crecimiento personal mediante recursos propios. Asimismo, se observa una mejora en cuanto a la unión familiar que se presenta en las declaraciones expuestas sobre resoluciones de problemas mediante la aceptación de las diferencias y la tolerancia.

Hochswender, Martin y Morino (2002) señalan que una de las metas subyacentes del budismo es establecer una sociedad pacífica y segura. La transformación interior representa un importante medio para solucionar muchos de los problemas de la sociedad actual y facilitar una convivencia pacífica (Rojas, 2011). Estas conductas se vieron reflejadas también fuera del entorno familiar, como por ejemplo en la escuela y el trabajo. Por ello, se observa una mejora en las relaciones con el entorno, demostrando la importancia del componente comunitario en la búsqueda del bienestar, en el desarrollo de diferentes habilidades sociales, como por ejemplo mayor empatía y preocupación por el medio que los rodea.

Levine (2000, como se citó en Mikulas, 2007; Pantoja, 2010) refiere una serie de puntos en común 
entre el budismo y la psicología occidental. Ambos se preocupan por aliviar el sufrimiento humano y comparten el ideal de maduración y crecimiento de la persona. Además, reconocen que la mente funciona en un nivel superficial y profundo.

Los resultados obtenidos, invitan a enfatizar el budismo como un medio para alcanzar el bienestar psicológico propuesto por Ryff y Keyes (1995). Se observa que, para los budistas, el significado de bienestar contiene un componente extra; el factor comunitario. Los participantes señalan en sus discursos la importancia y el valor que tiene para ellos el bienestar social. La meta principal para esta filosofía de vida es enseñar a los demás que, a través de su práctica, se puede encontrar un equilibrio personal que les brinde una mejor calidad de vida. Mencionan que todo cambio comienza por uno mismo pero que toda actitud que uno tenga se ve reflejada en el entorno. Por lo tanto, si uno trata bien a su entorno, este responderá favorablemente.

La siguiente cita muestra como un participante de la presente investigación pone en práctica esta filosofía de vida.

(...) Me di cuenta que la felicidad no radica en el exterior de uno, la felicidad radica dentro de uno y como tú te sientas frente a las situaciones que puedas tener, sean positivas o negativas (...) En nuestro propósito de la lucha, nosotros no solo buscamos la felicidad para uno mismo sino también para los demás a través de nuestro cambio personal (...) siempre trato de basarme de las experiencias que tengo aquí dentro de la organización porque son las que me han llenado más. Explicarles a las personas que practican o no practican el budismo sobre temas diversos y ver en ellos que llegas a su corazón. Ese tipo de cosas, hacen que yo me sienta bien y que sienta que de alguna manera estoy contribuyendo para que mi país cambie (Sujeto 3).

En conclusión, se encuentra que el budismo brinda un aporte a la psicología positiva, ya que enseña a reencontrar y valorar los recursos propios de la persona para que esta pueda llegar a alcanzar un equilibrio consigo misma y con su entorno que finalmente lo lleve al bienestar.

Resultaría interesante poder medir el nivel de bienestar de los participantes budistas. Por ello, se recomienda realizar un estudio cuantitativo utilizando la escala de bienestar psicológico propuesta por Ryff y Keyes (1995) para así contrastar los resultados señalados en esta investigación. Asimismo, se podría realizar estudios en participantes de otras ramas del budismo.

\section{Referencias}

Almansa, G., Budia, M., Del Mar Peña, M., Fernández Ozcorta, E., López, J., Márquez, M, ... \& Zafra, J. (2014). Efecto de un programa de Mindfulness sobre variables motivacionales y psicológicas en educación primaria. E-motion, Revista de Educación, Motricidad e Investigación, 3, 120133.

Recuperado http://www.uhu.es/publicaciones/ojs/index.php/e -moti-on/article/view/2449/2331

Anguas-Wong, A., Bilbao, M., Burga, G., Calderón-Prada, A., Espinosa, A., Feijoo, A. \& Yamamoto, J. (2007). Revista de Psicología, 25(2), 236-273. Recuperado de http://www.psiucv.cl/wpcontent/uploads/2012/11/1413-5453-1-PB.pdf

Ashboul, A. (2005). La Relación Polémica entre la Lógica de la Filosofía y el Dogma de la Religión. Nómadas, Revista Crítica de Ciencias Sociales y Jurídicas, 12(2), 1-8. Recuperado de http://pendientedemigracion.ucm.es/info/nomad as/12/amalshboul.pdf

Berzin, A. (1988). El atractivo del budismo en el mundo moderno. Recuperado de http://studybuddhism.com/web/es/archives/appr oaching_buddhism/introduction/appeal_buddhis m modern world.html

Bustamante, J. (2004). El despertar y la felicidad en el budismo. Polis, Revista de la Universidad $\begin{array}{lll}\text { Bolivariana, } & 3(8), & 1-15 .\end{array}$ doi:http://polis.revues. org/5959

Chávez, A. (2006). Bienestar Psicológico y su influencia en el rendimiento académico de estudiantes de nivel medio superior (Tesis de maestría, Universidad de Colima, México). Recuperado de http://digeset.ucol.mx/tesis posgrado/Pdf/ALFO NSO CHAVEZ URIBE.pdf

Chávez, S. (2008). Bienestar psicológico en practicantes de yoga (Tesis para grado de Licenciada en Psicología). Recuperado del Repositorio Digital de la Pontificia Universidad Católica del Perú http://tesis.pucp.edu.pe/repositorio/handle/1234 56789/627

Ciancaglini, E. (s.f.). Manual de Introducción al Budismo. Recuperado

de http://budismodelasiembra.weebly.com/uploads/ 1/3/4/4/13444978/manual de introduccion al b udismo.pdf

Córdova, A. (2004). Apuntes Sobre el Budismo. Tübingen: Instituto Mexicano de Psicoanálisis. Recuperado de

http://btmar.org/files/files/erich fromm texto po stumo buddhismo.pdf

Denegri, M., García, C., González, N., Orellana, L., Sepúlveda, J. \& Schnettler, B. (2014). Bienestar Subjetivo y Satisfacción con la Alimentación en estudiantes universitarios: Un estudio cualitativo. Summa Psicológica UST, 11(1), 51-63. doi:10.18774/summa-vol11.num1-144

Diener, E. (1994). El bienestar subjetivo. Intervención psicosocial. Revista sobre igualdad y calidad de vida, 3(8), 67-113. Recuperado de http://www.copmadrid.org/webcopm/publicacion es/social/1994/vol2/arti5.htm

Ekman, P., Davidson, R., Ricard, M. \& Wallace, B. (2005). Buddhist and psychological perspectives on emotions and well-being. Current Directions in Psychological Science, 14(2), 59-63. Recuperado de https://sbinstitute.com/aw/wellbeing.pdf

González Rey, F. (2006). Investigación cualitativa y subjetividad: La investigación cualitativa como 
producción teórica: una aproximación diferente. Guatemala: Oficina de Derechos Humanos del Arzobispado de Guatemala.

González, A., García-Viniegras, C. \& Ruiz, A. (2014). Consideraciones acerca del Bienestar Psicológico. Revista Electrónica de Psicología Iztacala, 17(3), 1108-1140. Recuperado de http://www.iztacala.unam.mx/carreras/psicologia /psiclin/vol17num3/Vol17No3Art11.pdf

Gutiérrez, G. (2011). Meditación, Mindfulness y sus efectos Biopsicosociales. Revisión de Literatura. Revista Electrónica de Psicología Iztacala, 14(2), 26-32. Recuperado de http://revistas.unam.mx/index. php/repi/article/vie wFile/26036/24511

Hernández, R., Fernández, C. \& Baptista, P. (2006). Metodología de la investigación. México: McGraw-Hill.

Lama, D. (2014). El arte de la felicidad. Santiago, Chile: Editorial Debolsillo.

Mañas, I. (2009). Mindfulness (Atención Plena): La Meditación en Psicología Clínica. Gaceta de Psicología, (50), 13-29. Recuperado de http://www.psicologiamindfulness.es/assets/pdfs 39884-16.pdf

Martínez, M. (2006). La investigación cualitativa (síntesis conceptual). Revista de Investigación en Psicología, 9(1), 123-146. Recuperado de http://sisbib.unmsm.edu.pe/bvrevistas/investigac ion psicologia/v09 n1/pdf/a09v9n1.pdf

Mikulas, W. (2007). Buddhism \& Western psychology: Fundamentals of integration. Journal of Consciousness Studies, 14(4), 4-49. Recuperado http://uwf.edu/wmikulas/documents/Buddhism.p df

Pantoja, C. (2010). Budismo y su aplicación en la Psicoterapia Postmoderna (Tesis de maestría, Universidad Mayor, Santiago, Chile). Recuperada de http://www.libroesoterico.com/biblioteca/ESPEC IALES2/BUDISMO-Y-SU-APLICACION-EN-LAPSICOTERAPIA-POSMODERNA.pdf

Ramos, A. (2009). Muestreo no probabilístico. Universidad Nacional Experimental Francisco de Miranda. Recuperado de http://es.slideshare.net/anthonymaule/muestreono-probabilístico

Rojas, T. (2011). Felicidad en Jóvenes Practicantes del Budismo de Nichiren Daishonin (Tesis de Licenciatura, Universidad de Lima, Lima).

Ryff, C. (1989). Happiness Is Everything, or Is It? Explorations on the Meaning of Psychological Well-Being. Journal of Personality and Social Psychology, 57(6), 1069-1081. doi:10.1037/0022-3514.57.6.1069

Ryff, C. \& Keyes, C. (1995). The Structure of Psychological Well-Being Revisited. Journal of Personality and Social Psychology, 69(4), 719-727. doi:10.1037/0022-3514.69.4.719

Sánchez, F. (2001). El corazón de las enseñanzas de Buda. Barcelona: Oniro.
Soka Gakkai Internacional. (2008). El significado de Nammyoho-renge-kyo. Recuperado de http://www. sqi. org/es/acerca-denosotros/conceptos-filosoficos/nam-myohorenge-kyo.html

Schnettler, B., Miranda, H., Sepúlveda, J. \& Denegri, M. (2011). Satisfacción con la alimentación y la vida, un estudio exploratorio en estudiantes de la Universidad de la Frontera, Temuco-Chile. Psicología \& Sociedade, 23(2), 426-435. doi:10.1590/S0102-71822011000200024

Strauss, A. \& Corbin, J. (1990). Basics of qualitative research: Grounded theory procedures and techniques. California: Sage Publications.

Trejo, G. (2010). Religión: Definición y Naturaleza. Filosofía de la Religión. Recuperado de http://philosofiareligion.blogspot.com/2010/05/rel igion-definicion-y-naturaleza.html

Véliz Burgos, A. (2012). Propiedades psicométricas de la escala de bienestar psicológico y su estructura factorial en universitarios chilenos. Psicoperspectivas, 11(2), 143-163. doi:10.5027/psicoperspectivas-Vol11-Issue2fulltext-196

Zubieta, E., Fernández, O. \& Sosa, F. (2012). Bienestar, valores y variables asociadas. Boletín de Psicología, 106, 7-27. Recuperado de http://www.uv.es/seoane/boletin/previos/N1061.pdf 